\title{
DEL ESTIGMA DEL NEGOCIO AL NEGOCIO DEL ESTIGMA. LA PRENSA POPULAR ARGENTINA Y SU RECUPERACIÓN EMPRESARIAL E INSTITUCIONAL
}

\section{From the Business' Stigma to the Making of Stigma Profitable. Popular Press in Argentina and its Corporate and Institutional Recovery}

\section{Do estigma do negócio ao negócio do estigma. A imprensa popular argentina e sua recuperação empresarial e institucional}

ARAOZ ORTIZ, Leandro. Instituto de Investigaciones Gino Germani, Universidad de Buenos Aires (IIGG-UBA), CONICET (Argentina)

laraozortiz@gmail.com

Fecha de recibido: 30 de julio de 2015

Fecha de aceptado: 8 de noviembre de 2015

\section{RESUMEN}

El artículo recorre el devenir de la prensa popular argentina desde sus inicios a comienzos del siglo xx hasta su aparente "resurgimiento" a principios de la década del 2010. Las transformaciones del mercado periodístico permiten observar un desplazamiento de su lugar, que se define como marginal: marginalidad señalada no por el volumen de sus (cuantiosas) ventas, sino porque dichos productos demarcan el límite de lo permitido en la práctica periodística, que conservaba a la prensa como reducto del modelo liberal de ciudadanía. Las transformaciones en las lógicas de producción y consumo mediático permiten observar cómo las empresas que antes denostaban a este sector incorporaron a sus carteras publicaciones populares que se diferencian en algunos aspectos de sus antece- 
sores amarillistas. Estas discusiones sobre el sensacionalismo, la cultura popular y la emotividad en la prensa es un punto central para contextualizar la discusión de los populismos en los países de la región.

Palabras clave: prensa popular, diarios populares, Argentina, populismo.

\begin{abstract}
The paper analyses the evolution of Argentinian popular press since its birth in the early twentieth century to its apparent "resurgence" in the decade of 2010. The transformations of the newspaper's market allow to observe a shift of its place defined as marginal: marginality appointed not by the volume of their (substantial) sales, but because those products demarcate the permitted limit in journalistic practice, which retains the press as a stronghold of the liberal model of citizenship. The changes in the logics of media production and consumption allow observing how companies that previously vilified this sector, joined to their portfolios popular publications which differ in some aspects from its sensationalist predecessors. These discussions on sensationalism, popular culture and emotion in the press are a central point to contextualize the discussion of populisms in the countries of the region.
\end{abstract}

Keywords: popular press, popular newspapers, Argentina, populism.

\title{
RESUMO
}

O artigo recorre devir da imprensa popular argentina desde os seus inícios a começos do século xx até seu aparente "ressurgimento" a princípios desta década (2010). As transformações do mercado jornalístico permitem observar um deslocamento de seu lugar que se define como marginal: marginalidade assinalada não pelo volume de suas (quantiosas) vendas, mas porque ditos produtos demarcam o limite do permitido na prática jornalística, que conservava à imprensa como reduto do modelo liberal de cidadania. As transformações nas lógicas de produção e consumo mediático permitem observar como as empresas que antes injuriavam a este setor incorporaram as suas carteiras publicações populares que se diferenciam em alguns aspetos de seus antecessores sensacionalistas. Estas discussões sobre o sensacionalismo, a cultura popular e a emotividade na imprensa é um ponto central para contextualizar a discussão dos populismos nos países da região.

Palavras-chave: imprensa popular, diários populares, Argentina, populismo. 


\section{Introducción}

Los abordajes sobre la prensa popular y el sensacionalismo dieron lugar a interesantes reflexiones sobre la relación entre la comunicación, la cultura y la desigualdad social. En el caso argentino, resulta llamativa la falta de estudios específicos sobre este sector, a diferencia de otros países de la región e incluso de otros continentes. Esta carencia responde a tres elementos, que funcionan más bien como hipótesis: en primer lugar, se puede observar un desplazamiento de la prensa en general como consumo cultural y principal vía de acceso a la información por parte de los sectores populares y su reemplazo por medios audiovisuales e incluso digitales. Dicha tendencia se extiende a casi todo Occidente, con las salvedades que se desarrollarán más adelante. En América Latina, la tradición académica se focalizó en este segmento en la década de 1980, en un marco de reflexión que ubicó a la prensa popular como contracara de la prensa "seria" (Martín-Barbero, 2010; Steimberg, 1987; Sunkel, 1985). Progresivamente, los estudios sobre cultura popular fueron decreciendo en relevancia, y si bien se registran importantes trabajos en diversos países latinoamericanos, nuevamente Argentina es una excepción: Ecuador (Checa Montúfar, 2003), Perú (Gargurevich Regal, 2000), Bolivia (Lanza, 2010; Torrico, 1999), por citar solo algunos ejemplos. En la mayoría de los casos, el foco está puesto en la crónica roja, género que identificó históricamente a la prensa popular y la asoció casi de manera ineludible con el sensacionalismo y las prácticas más cuestionadas que sirvieron como punta de lanza para la propuesta de modernización que se analizará más adelante.

En el segundo punto se puede observar que una serie de transformaciones de los lenguajes periodísticos y mediáticos le quitaron especificidad al soporte y a su estética principal, denominada históricamente sensacionalismo o amarillismo. Aquí se engloban la predominancia de la imagen, la disposición gráfica y, sobre todo, el quiebre con el tono solemne de la prensa seria tradicional, que permitió que algunos autores identificaran el "ocaso triunfal" de la prensa amarilla (Steimberg, 2000).

Un tercer pliegue para señalar en este fenómeno, derivado de los anteriores, aparece a partir de una supuesta crisis de los discursos sobre lo popular (y sobre la cultura popular) consolidado a principios de los años noventa, cuyo desarrollo y estadio actual es necesario relevar. El contexto de estos cambios está signado por los procesos políticos neopopulistas o populistas conservadores que se identificaron en el plano cultural -para el caso argentino- en lo que algunos autores han denominado plebeyización de la cultura. Se entiende por tal, el proceso por el cual determinados "bienes, prácticas, costumbres y objetos tradicionalmente marcados por su pertenencia, origen o uso por parte de las clases populares, pasaron a ser apropiados, compartidos y usados por las clases medias y altas" (Alabarces \& Silba, 2014, p. 53). Los principales elementos que permiten comprender este fenómeno son dos: en términos globales, una de las consecuencias del posmodernismo fue poner en cuestión el elitismo cultural (McGuigan, 2000) tornando borrosas las fronteras entre los consumos que se distribuían de manera segmentada sin contradicciones evidentes. Paralelamente, en términos locales cabe destacar que el proceso de transformaciones neoliberales llevadas a cabo en Argentina por el gobierno de Carlos Menem implicó quebrar una barrera adicional: reestructurar el sistema productivo y la hegemonía con un fuerte contenido antipopular desde el movimiento político populista más importante del siglo xx argentino, el peronismo.

De esta manera, desde el interior del mismo movimiento, que desde mediados de los años 40 llevó adelante el proceso de configuración de las clases populares "mediante la integración socioeconómica y simbólica en términos 
de 'pueblo trabajador'" (Svampa, 2005, p. 163), se terminó expurgando el elemento plebeyo que caracterizó a dicho movimiento político, fenómeno que parece revertirse - $\mathrm{o}$ al menos matizarse- a partir del surgimiento a principios de este siglo con los gobiernos encabezados por Néstor Kirchner y Cristina Fernández. Maristella Svampa (2011) llama la atención sobre esta cuestión: es sorprendente la capacidad del peronismo para reactualizar y potenciar los componentes nacional-populares (revalorizar el Estado, recuperar la centralidad del líder - luego del "que se vayan todos" que caracterizó a la crisis del 2001-y la reorganización de estructuras de militancia sindical, social, política y cultural) luego del notable giro neoliberal realizado por el gobierno de Carlos Menem. En este contexto, es necesario observar qué elementos permiten seguir hablando hoy (y en qué términos puede hacerse) de conceptos como 'cultura popular' y de las producciones que nos insertan en ese campo de investigación.

Teniendo en cuenta este contexto, en el presente artículo se analiza el mercado de diarios populares en Argentina, sus orígenes y sus transformaciones recientes. Dichos cambios son particularmente llamativos en el marco de un sector cuya historia no es necesariamente amplia en comparación con otros países de la región. Esta particularidad permite dar cuenta de ciertos elementos en común y, a su vez, marcar ciertas particularidades que se presentaron tardíamente y, por consiguiente, con mayor claridad y celeridad.

Las nuevas características que adquirió esta prensa no resolvieron, ciertamente, el eje central para abordar este fenómeno: un cuestionamiento por la hegemonía y las desigualdades que se presentan en el plano cultural en las sociedades latinoamericanas contemporáneas. Por ello, mantener la pregunta sobre la existencia de una forma popular de informar e informarse mantiene vigente la pregunta por la identidad, el consumo, la estética y la política, ya que indaga sobre la construcción de las desigualdades y sobre los desafíos tendientes a construir un periodismo y una cultura democrática.

\section{La prensa popular en Argentina premercado}

En casi todo el mundo la prensa popular ha sido pensada como un elemento marginal, una suerte de desviación de su par (auto)denominada seria y que, por lo tanto, la ubica en el margen del periodismo mismo. Por tal motivo se erige como un elemento díscolo y disruptivo que debía ser eliminado por representar un peligro para la sociedad, como tempranamente denunciaron diversos agentes sociales: académicos, religiosos y referentes de las viejas empresas editoriales que lanzaron una guerra moral contra la prensa amarilla (Campbell, 2001; Schudson, 1981). En muchos casos, esta suerte de corrupción del modelo liberal democrático de la prensa se adjudicaba a la evidente mercantilización de la prensa, producto de sus relaciones espurias con la publicidad. Como señalaba tempranamente (en 1910) Edward A. Ross "No cabe esperar que el periódico se mantenga digno y serio ahora que abastece a millones de gentes comunes, en lugar de hacerlo, como antes, a las clases profesionales y empresariales" (Ross, 2001, p. 191).

En el caso argentino, el ambicioso proyecto cultural de las élites porteñas durante el siglo xix formó parte de un proceso de modernización "que implicó que muchos indicadores culturales se ubicaran en valores cercanos a los europeos” (Mastrini \& Becerra, 2006, p. 77) gracias a una política educativa que permite que hoy en día los índices de alfabetización alcancen cerca del $96 \%$ de la población, dato fundamental para comprender el desarrollo temprano de la prensa escrita y la industria editorial local. Sin embargo, este proceso no redundó en la consolidación de una prensa liberal, formalmente establecida desde el siglo xıx, sino en una profusa prensa obrera que marcó la 
lectura de los trabajadores y la construcción del mundo del trabajo como elemento de discusión y organización (Adamovsky, 2012; Lobato, 2009).

Es pertinente recordar que el origen de la prensa misma se remonta a los pasquines revolucionarios y panfletos, el modelo de la antigua prensa popular, sindical y otras publicaciones de fuerte penetración en los sectores populares. En el caso chileno se destaca el fenómeno de las liras populares que reconstruyó Guillermo Sunkel (1985). En estos medios predominaban los enfoques que hoy denominamos como sensacionalistas: los relatos descarnados, la oralidad, un lenguaje cómplice con el lector; las imágenes (con las limitaciones técnicas de la época), y los juicios de valor fuertemente morales sobre los hechos relatados. Esta herencia no está exenta de modificaciones, por eso la prensa popular permite observar las instancias de cruce e interrelación entre la cultura popular y la industria cultural, en especial sus referencias múltiples y sus negociaciones. Es precisamente su análisis como protoperiodismo, destaca Martín-Barbero (2010, p. 205), lo que permite no solo encontrar las raíces de la prensa sensacionalista contemporánea sino también dar cuenta tanto de sus aspectos estéticos (una forma de leer y narrar, obras pensadas para ser leídas en voz alta y que cuentan una historia) como temáticos (la ampliación de lo político, o más precisamente, lo público y lo social).

\section{Pensar la prensa popular}

Stuart Hall (1984) describe el surgimiento de la prensa popular como un producto de una importante transformación en las relaciones sociales, culturales y económicas. La prensa "comercial y popular" (p. 97)¹ surge a fines del siglo xix en Inglaterra -y también en otros países industrializados - como una prensa "organizada por el capital «para» las clases obreras" (p. 97), producto de una inserción de un público obrero maduro y alfabetizado que apunta a representar - en varios sentidos- a todo un sector pujante en la nueva sociedad industrial. En este proceso, explica Hall (1984), se puede observar una expropiación por parte del capital de lenguajes, formas y estéticas que predominaron en las expresiones tradicionales (prensa obrera, indígena, panfletaria) y que se organizan como negocio para las nuevas clases populares recientemente alfabetizadas.

A partir de este momento, los periódicos populares y el sensacionalismo se convirtieron en conceptos que parecían ir de la mano hasta el día de hoy, en tanto se caracterizan por el lenguaje estridente y virulento que se hereda (transformaciones analizadas detalladamente por Hall) de dichas publicaciones. En ambos (tipo de prensa y estilo) recayó una caracterización peyorativa que fue aumentando de manera directamente proporcional a la expansión de sus ventas en la disputa con los periódicos "serios". Esta prensa liberal le ha dedicado a la prensa amarilla -como destaca para el caso norteamericano Joseph Campbell (2001) - editoriales y notas para boicotear a estos periódicos, construyendo una suerte de estigma a partir de su estilo, para instalarlo como una característica fuertemente desacreditadora. La lista de epítetos es profusa: destaca Mar de Fontcuberta (2006) que el sensacionalismo ha estado siempre ligado a dos aspectos negativos que contribuyeron a su estigmatización: la falta de veracidad y una marcada exacerbación de los aspectos morbosos de las noticias. En este sentido, Campbell (2001) remarca que dicha campaña de boicot resultó ineficiente -en tanto no logró destruirlos- pero eficaz en la carga del desprestigio que arrastran aún dos siglos después de su surgimiento. Además, la variedad de apelativos dan

1 Destacado en el original 
cuenta del ensañamiento con estos medios: prensa amarilla, sensacionalista y popular son algunos de los términos más comunes, aunque también cuenta con calificativos más crueles (prensa basura, del hígado, etc.); algunas de estas definiciones son recopiladas, de manera parcial, por Mar de Fontcuberta (2006). Por su parte, Marcia Amaral (2006) llama la atención sobre las definiciones cromáticas (roja, amarilla, rosa e incluso la más explícita marrón). Los periódicos de mayor trayectoria denunciaban y boicoteaban a estos nuevos competidores, acusándolos fundamentalmente de abusar de recursos de discutible ética para atraer más lectores. Estas nuevas camadas recientemente ilustradas serían, de acuerdo a esta evaluación, más vulnerables a estas artimañas, de acuerdo a lo que fustigaban desde sus editoriales. A su vez, los sectores letrados ligados a la literatura también se expresaban en sentido coincidente. Este enfoque paternalista y etnocentrista que daba cuenta de una continuidad con el modelo cultural de la Ilustración, que si bien era inaccesible para las masas populares, era igualmente exigido como patrón general de cumplimiento (Bauman, 1997).

Pero en los últimos años, esta división entre prensa denominada sensacionalista o amarilla y la prensa "seria" se habría ido difuminando y la oposición estilística perdió su funcionalidad descriptiva, a medida que los medios "serios" fueron adaptando formatos y estrategias de sus otrora pares antagónicos, destacándose la fisura entre lo público, lo privado y lo íntimo (Steimberg, 2000).

A partir de estas observaciones es difícil seguir utilizando los criterios clásicos, al punto que el sensacionalismo como categoría parece desplazada: es posible hablar de niveles de sensacionalismo o amarillismo, en los términos en los que los plantean Awad y Soto (2001). En este caso, el amarillismo se aprecia como un instrumento utilizado para capturar la atención del lector que se extiende a la totalidad del periodismo, en tanto la apelación a las emociones - de distinto tipo-conforma una estrategia de conexión con el lector que dista de ser interpelado por una lógica narrativa ascética o pretendidamente neutral.

No obstante, esta apelación a lo emotivo se comprendió desde un principio como una estrategia autóctona de la prensa popular y se englobó en la lógica del sensacionalismo, pensándolo siempre como una desviación. En otro trabajo posterior, Sunkel (2002) retoma su análisis de la prensa sensacionalista chilena, pero en este caso ya no presenta un análisis comparativo con la prensa de izquierda, como en su clásico Razón y pasión en la prensa popular..., sino que analiza el periódico La Cuarta del grupo COPESA (propietario también de La Tercera). El autor chileno profundiza algunas de las reflexiones de su trabajo de los años 80; si bien se focaliza fundamentalmente en la recepción, allí destaca que dicho objeto muestra una lógica cultural diferente a la de la prensa seria, que se conecta con una estética melodramática que altera la separación racionalista entre temáticas serias y las que carecen de valor, que se atreve a tratar los hechos políticos como objetos dramáticos y a romper con la "ideología de la objetividad" (Sunkel, 2002, p. 19). En este sentido, el autor sostiene que esta lógica fue reprimida mediante el rechazo de la "educación formal y la política seria" (Sunkel, 2002, p. 19) y que sobrevive en la industria cultural.

Si, como sostiene Martín-Barbero (2010), existe la posibilidad de leer en los textos masivos rasgos propios de - o al menos originalmente asociados a - los sectores populares y su cultura, el abordaje de la prensa popular puede configurarse como un espacio de articulación entre lo popular y lo masivo. Es decir, que permitiría describir los elementos de identificación que son utilizados por los medios masivos que remiten a la cultura popular y a los mecanismos de estilización y homogenización (Martín-Barbero, 1983) que transforman y reconvierten a la prensa popular (su lenguaje, sus temas, sus formatos) en un producto de masas, y simultáneamente poder identificar cuáles elementos - si los hay-sobreviven en ella. 


\section{La prensa popular en el mercado}

A principios del siglo xx, el 'nuevo periodismo' profesionalizado de las grandes ciudades "incorpora nuevos lenguajes, ideas renovadas, temáticas y secciones diferentes a la prensa para permitir su salto a escala industrial de producción" (Becerra, 2010, p. 9). Es así como la aparición en 1913 del diario Crítica constituye un hito en la incorporación de los sectores populares como consumidores de la prensa del país, que para la década del 30 alcanza la tirada de 350000 ejemplares, insoslayable para la época y casi impensable para la actualidad. Como sostiene Sylvia Saítta (1998) en su historia del mítico diario, el éxito de Crítica se explica por un nuevo pacto de lectura -o una estrategia político editorial-que rompe la distancia entre el lector y el medio generando propuestas de cercanía. De esta manera Crítica aparece como un actor central de la modernización del campo periodístico y "en el mismo movimiento, plantea una relación no mediada con el lector en el gesto de pasar por alto las reglas capitalistas del mercado moderno" (Saítta, p. 73), escamoteando así su carácter de mercancía.

La autora propone en su mirada histórica destacar dos momentos: uno "enunciativamente popular", donde se proponen una serie de consideraciones sobre la relación entre el público destinatario y el medio-empresa, y otro de "efectiva defensa de los intereses populares", en tanto responde a los intereses de esta clase social (pp. 55 y ss.). Para justificar esta afirmación, la autora recalca algunos ejemplos destacados como la defensa desde sus páginas de Kurt Wilckens, militante perseguido por ajusticiar a un fusilador de obreros. El diario lo presenta como un héroe idealista y en estos términos defiende "efectivamente" los intereses populares, mientras que su apoyo a la dictadura de 1930 habría traicionado dicho compromiso.

En 1923 Crítica define "discursivamente un pacto de lectura a partir del cual se postula como representante de los intereses populares", una "voz del pueblo" (Saítta, p. 65) materializada por periodistas que, lejos de ser inaccesibles, son presentados por el diario de manera claramente humanizada. Pero su éxito no se explica únicamente por el formato y su narrativa (el sensacionalismo, el lenguaje crudo y paralelamente jocoso), sino por lo que hoy se denominaría una pionera estrategia de mercadotecnia: su distribución en las barriadas populares, las alianzas con los 'canillitas' -vendedores de los puestos de diarios-, los obsequios y campañas de solidaridad y beneficencia, diversos artilugios que continúan al día de hoy los diarios populares y que se han extendido a otras publicaciones.

Pasada su época de oro de los años 20, y tras su explícito apoyo al golpe de Estado contra Hipólito Yrigoyen, el diario de Botana (Crítica) comienza a perder lectores e incidencia. En el año de 1962 se imprimió su último ejemplar, dejando un espacio vacío que no tardó en llenarse.

El 29 de julio de 1963 aparece en las calles de Buenos Aires, Crónica, el intento empresarial contemporáneo más antiguo de construir un diario popular que retomara los principales ejes temáticos y formatos gráficos de la prensa sensacionalista norteamericana y, muy especialmente, los enfoques que este formato encontraba en otros países latinoamericanos. Su fundador, Héctor Ricardo García, luego de haber trabajado casi desde niño como reportero gráfico, admite haber encontrado en los países vecinos algo completamente nuevo, que muchos años después intentaría reconstruir con sus propias palabras:

...usaban color, publicaban grandes títulos, algunas veces ingeniosos por no decir humorísticos, dedicaban mucho espacio al deporte, a las noticias de policía, al espectáculo. Contrastaban con la supuesta seriedad de los de Buenos Aires, que desde su tapa hasta su página central se ocupaban sólo de temas 
internacionales, de discursos de los parlamentarios europeos o en las Naciones Unidas. Los temas popu-

lares prácticamente no existían (García, 1993, p. 46).

Como suerte de mito autocelebratorio, García (1993) se muestra fascinado por la prensa popular chilena y talla su sueño de llevarlo a la práctica en el mercado porteño, como finalmente lo logró unos años después. Llamativamente pasa por alto en su autobiografía la experiencia de Crítica, salvo alguna referencia menor. Crónica se imprimió casi sin interrupción durante sus más de 50 años de vida manteniendo, más allá de su conformación accionaria como empresa, aspectos fundamentales de su estilo.

El $1^{\circ}$ de julio de 1974, el día de la muerte del presidente Juan Domingo Perón, nace otro de los medios de mayor envergadura en la prensa popular local: Diario Popular. Este comenzó a tomar fuerza a partir de un hecho político trascendente: la prohibición que el gobierno de María Esther Martínez de Perón ejerció sobre Crónica, que incluyó diversas clausuras. Actualmente Diario Popular es el tercer diario más vendido de Argentina.

Estos vaivenes editoriales parecen oscilar entre el oportunismo empresarial y político, donde las censuras y las malas jugadas marcaron el inicio o el ocaso de los proyectos, como lo mostró para el caso peruano Macassi Lavander (2001). Las transformaciones que pueden observarse en el mercado de prensa argentino en el año 2011, que se analizan a continuación, indican una nueva oportunidad para estos periódicos en plena discusión electoral que llevará finalmente a la reelección de Cristina Fernández.

\section{¿Renovación de la prensa popular?}

En paralelo a los presagios del fin de la prensa escrita, en 2011 dejaba de editarse uno de los históricos referentes de la prensa sensacionalista británica, el tabloide News of the World, propiedad del multimillonario Rupert Murdoch, a causa de un escándalo político de enormes dimensiones. La denuncia por espionaje contra uno de los conglomerados mediáticos más importantes del mundo terminó no solo con la publicación de uno de los diarios más vendidos del mundo sino que produjo un cimbronazo político y una serie de debates sobre la capacidad del sistema de "autocontrol británico de la prensa" (Pauner Chulvi, 2013) que se hizo extensivo a todo el mundo, como otros debates sobre la regulación y el crecimiento de los conglomerados mediáticos (Arsenault \& Castells, 2008; Carlson \& Berkowitz, 2014; Keightley \& Punathambekar, 2012). Aun con estos debates en pleno auge, el mercado de prensa popular en Buenos Aires se dinamizaba con el lanzamiento, en un mismo día (2 de mayo) de dos diarios: Muy - del grupo Clarín-y Libre - de Editorial Perfil-que salían a la calle presentándose como dos nuevos diarios populares.

La jugada de Clarín y Perfil no parece descabellada. A pesar de la caída en las ventas de diarios que se registró en la mayoría de los matutinos, el mercado local tuvo un principal ganador: Diario Popular vendió en abril de 2011 más de 90000 ejemplares diarios en promedio, es el tercero en ventas según datos oficiales del Instituto Verificador de Circulaciones (Ivc) y era por entonces el único diario de los diez de mayor venta que durante los últimos seis años había tenido un crecimiento sostenido. Crónica (que no es medido por dicho índice) vende alrededor de 40000 ejemplares según estimaciones extraoficiales. Solo entre ellos dos llegan al 80\% de ventas de La Nación y la mitad de ventas del diario más vendido del país, Clarín. El contexto regional tampoco desentona: en Perú la prensa "chicha" (como se denomina a una parte de los periódicos sensacionalistas) alcanza el 50\% del mercado, mientras que solo Trome vende cerca de 750000 ejemplares diarios. Según datos de 2014de la Asociación Mundial de Periódicos y Editores de Noticias (WAN-IFRA), de los cinco periódicos occidentales más vendidos a nivel mundial, 
tres se encuentran en este espacio: Bild Zeitung de Alemania y The Sun y Daily Mail de Inglaterra, si bien han sido afectados en los últimos años por la tendencia a la baja que se registra en Europa.

La lógica de las tres S (sex, sport, scandal - sexo, deporte y escándalo), que según Díaz Nosty (2007) orienta al periodismo tabloide (como se lo denomina en Gran Bretaña), marca de alguna manera la línea de los medios analizados, pero lentamente Libre y Muy fueron buscando sus especificidades. Por un lado, el modelo del tabloide británico, con The Sun y Daily Mirror como paradigma, al cual de manera bastante clara se adhirió Libre: títulos de escándalo - generalmente ligados al sexo o el consumo de drogas de políticos y personajes de la farándula-, pocos colores y fuertes contrastes - negro y rojo, como predominaban en su logo-. En el caso de Muy, su modelo está anclado más a la prensa latinoamericana, fundamentalmente a los nuevos diarios populares brasileños: muchos colores, humor, testimonios de lectores y pequeñas historias, en sintonía con lo que Amaral (2006) observa en el 'nuevo periodismo popular' que se afianza en las grandes ciudades brasileñas. En un exceso de simplificación, el modelo brasileño inspiró y orientó el surgimiento de Muy mientras que Libre apostó al modelo tabloide y con alguna cercanía a la prensa chicha (Cappellini, 2004; Gargurevich Regal, 2002), esquiva la inserción en el mercado local.

\section{Prensa popular en el país populista}

En Argentina la historia de la prensa popular es anterior al peronismo; sin embargo, es imposible comprender ese fenómeno -como tantos otros - por fuera de ese marco de referencia que constituye este particular populismo. Como se señaló, la incorporación masiva de los nuevos lectores al mercado de la prensa gráfica se dio con Crítica, que se comenzó a imprimir un año después de la Ley de Sufragio Universal de 1912. Dicha ley permitiría, casi cuatro años después, la asunción de Hipólito Yrigoyen como primer presidente apoyado por buena parte de las clases medias y obreras argentinas nucleadas en la Unión Cívica Radical. El diario fundado por Natalio Botana se opuso de manera sostenida a ese gobierno que incorporó a buena parte de la población a la vida política y llegó a promover su derrocamiento en 1930. Financiado originariamente por una fracción del partido conservador, Crítica sostenía un marcado desprecio por el yrigoyenismo. Más allá de algunas oscilaciones, su línea editorial se mantuvo en una clara posición aparentemente liberal contra la ignominia que implicaba ese proceso caracterizado como demagogo y caudillista, conceptos que se mantendrán para calificar al populismo peronista posterior (Adamovsky, 2012).

Llamativamente, más allá de sus efectivos posicionamientos políticos, Crítica configuró una construcción de la identidad obrera y de "los pobres", promoviendo, por ejemplo, acciones de beneficencia de los sindicatos y obrando mucha veces como defensor de los trabajadores, como plantea M. Karush (2013). Para el autor, hay una clara concordancia entre este proceso y el modelo cultural propuesto por el cine y el tango durante las décadas de 1920 y 1930, en las que las representaciones predominantes conformaban identidades basadas en la confrontación entre "pobres" y "ricos". Sobre este clivaje fundamental se conforman las imágenes de clase preponderantes que el peronismo retomará posteriormente como tópico central. Se puede de esta manera marcar una clara diferencia con otros países (como EE.uu.) donde el melodrama, por ejemplo, conformó discursos míticos de integración nacional, mientras que en el caso argentino "las imágenes populistas de la nación que circulaban en la cultura de masas eran profundamente polarizadoras" (Karush, 2013, p. 266). 
Con la llegada al poder de Juan D. Perón a mediados de la década de 1940, el periodismo se constituyó como un fuerte opositor a su gobierno, y la prensa popular no fue la excepción. El gobierno peronista contrapesó esta oposición con una férrea política de presión y expropiación de medios, conformando un espacio mediático oficialista (Arribá, 2009). Solo con el nacimiento de Crónica en 1963 surge una prensa popular afín al peronismo, por entonces proscripto en el país, tendencia política que el diario mantiene hasta hoy formalmente en propiedad de un grupo empresarial ligado a importantes sindicatos de dicha extracción política. Sin embargo, si bien se trata del diario popular con más años de circulación, tiene una cuota relativa en el mercado frente a sus competidores Diario Popular y Muy.

La mayoría de los gobiernos argentinos desde el retorno de la democracia en 1983 tuvieron oscilantes relaciones con los principales medios de comunicación. El Frente para la Victoria llegó a la presidencia en 2003 con la candidatura de Néstor Kirchner, quien fue sucedido por su esposa, Cristina Fernández, por dos períodos (2007-2011 y 2011-2015). Se trata de un gobierno que no reniega de su carácter populista -o "neopopulista" según algunos autores (Piva, 2013) - y ha sido posiblemente el que más se ha enfrentado a los medios dentro de un marco de garantía constitucional. Es decir: más allá de ciertas denuncias sobre el uso discrecional de la pauta oficial, el propio gobierno - fundamentalmente a partir de las presidencias de Fernández- sostuvo en su discurso de confrontación con los medios de comunicación, que estos defendían diversos intereses contrarios a las mayorías, en clara sintonía con los aspectos centrales de la retórica populista.

De esta manera, y si bien no existen hechos que se acerquen remotamente a persecuciones que en el país se vivieron en tiempos de dictadura e incluso en regímenes democráticos anteriores, se conformó un clima de confrontación en el que "el pluralismo es un emblema disputado a partir de la descalificación de la disidencia" (Becerra, 2015, p. 109). El resultado de esta tensión fue la consolidación de una suerte de sistema de posiciones polarizadas entre medios 'oficialistas' y 'opositores' que resultó, evidentemente, beneficioso para ambos sectores. Asimismo es necesario destacar que se consolidó una política de medios públicos que fortaleció y modernizó la producción con nuevos canales y propuestas, aunque por momentos en ciertos programas se observe un diseño endogámico que resulta controversial (Becerra, 2015). El modelo dicotómico descrito, simplificado a los fines de este trabajo, pretende confrontar a los medios calificados como opositores con una suerte de contra-discurso develando sus supuestos "verdaderos intereses" (políticos, neocoloniales, económicos, u otros, de acuerdo al momento político que se trate) que se esconden detrás de su pretendida independencia. Es en este contexto $-\mathrm{y}$ en medio de la campaña por la reelección de Cristina Fernández- en la que surgen los dos diarios a los que se hace referencia, Libre y Muy.

\section{Las discusiones de fondo}

Las controversias sobre la prensa popular contemporánea se organizan en torno a una dicotomía no explícita: entretenimiento vs. información. De esta forma se ubican en el centro de la escena aspectos que aparentan remitir a la estética y al estilo solamente, pero que hacen a la función misma de la prensa (y en términos más generales, de los medios) en la actualidad. La prensa popular tradicional tendría como foco el sensacionalismo, lo truculento y la vulgaridad. Su par "seria" o "de referencia" estaría libre de estos males, pero peca generando aburrimiento y demuestra un evidente atraso temático y estético frente a una población más dinámica que le exige a 
los medios nuevas formas de información ligadas -e incluso superpuestas- al entretenimiento, con la televisión como modelo.

Las palabras iniciales de los editores en los primeros números de Muy y Libre hacen explícito un desafío: la propuesta de una nueva narrativa en la que predomine la lucha contra el aburrimiento en el que supuestamente han caído los otros diarios. Esta lógica de entretenimiento se puede rastrear en sus páginas, donde predominan los temas más propios de las conversaciones cotidianas, antes que los temas de una agenda social. Estos elementos llevan a poner en cuestión en la esfera mediática global hasta qué punto sigue siendo válida la noción de agenda periodística y social que impuso como modelo el periodismo liberal (McCombs, 2006) y, en términos más amplios, qué tan compartida es en la actualidad la noción de opinión pública/espacio público en las sociedades fragmentadas y desiguales en las que se basa ese modelo (Habermas, 2004).

En términos de Rincón (2006), esta dicotomía podría pensarse a partir de la existencia en el periodismo de "dos gustos, dos industrias, dos modos de comprender el mundo" (p. 34), a saber:

la prensa ilustrada (mundo del poder + lectores con capacidad interpretativa + impacto en la toma de decisiones y entretenimiento del poder) versus prensa popular (vida popular + cultura baja + lectores

supersticiosos + impacto en la toma de decisiones y entretenimiento de los sectores populares) (p. 34).

Evidentemente ambos diarios (Muy y Libre) se proponen aportar a una pretendida modernización de la prensa popular, en lo que ven como un conservadurismo de los competidores preexistentes (Crónica y Diario Popular), y a su vez marcan progresivamente sus diferencias. Al mismo tiempo, se van diferenciando entre sí: Libre apuesta a los títulos de escándalo y otorga una presencia permanente a la farándula, lo cual se explica a partir de la afirmación de su jefe de redacción, Darío Gallo, de "hacer una revista todos los días" (Gallo citado por Gualda, 2011). En el caso de Muy, el diario propone cierta continuidad con el principal producto de la empresa (el diario Clarín), en un formato más claro y ágil, con menor impacto informativo, y un lenguaje en el que se privilegia lo local y el barrio, la provisión de servicios (a través de consultas con abogados, médicos y demás especialistas) y la ilustrativa presencia de algún famoso/a en situación cotidiana.

La fugaz vida de Libre, que circuló durante menos de un año, deja diversas hipótesis que no se debaten en este trabajo por falta de espacio: posibles errores de estrategia editorial, saturación del segmento de mercado, limitaciones propias del formato o simple derrota inevitable frente al poderoso multimedios.

Como reflexiona Amaral (2006), el conflicto prensa popular vs. prensa de referencia no puede ser tomado en términos estrictos ya que en muchos casos la prensa popular surge como subproducto de los conglomerados periodísticos. De esta manera, junto a los centenarios y prestigiosos (o, al menos, considerados "serios") matutinos conviven -incluso en las redacciones - formatos orientados a sectores populares que privilegian otras agendas y estéticas. El caso de Muy y Libre es un claro ejemplo, aunque tardío en comparación con otros conglomerados mediáticos de la región. El Mercurio de Chile o El Comercio de Perú, por ejemplo, han reformulado hace años sus estrategias en tanto entienden, como sostiene la propia Amaral (2006), que "es más difícil vender un periódico para alguien que tiene bajo nivel adquisitivo y poco hábito de lectura" ( p. 52). Incluso la Sociedad Interamericana de Prensa (SIP) organiza anualmente un Encuentro de Diarios Populares, el último de los cuales tuvo como eje de la convocatoria "Nuevos productos, más servicios y alianzas entre marcas" y se realizó en Buenos Aires en 2014; así como también implementó un Concurso de Portadas de Impacto en Diarios Populares, atentos a la originalidad y el talento que reconoce a estos productos. 
La principal divergencia en torno a la prensa popular, que puede apreciarse a partir del reordenamiento de este subcampo con el surgimiento de las dos nuevas publicaciones, tiene un marco económico: el crecimiento de los ingresos de los sectores populares argentinos durante la primera década del siglo, posterior a la crisis de 2001. Como analizan recientes investigaciones, puede observarse en los sectores populares de las economías emergentes, un incremento del acceso a bienes culturales históricamente asociados a las clases medias, como es el caso de los periódicos. Esto explicaría el crecimiento exponencial de la venta de ejemplares en países disímiles como Corea del Sur, India y Perú. Si bien en el caso argentino - con el mencionado consumo histórico de prensa por parte de los sectores populares- el análisis requiere incorporar otros factores. No obstante, el estudio de la prensa popular en los contextos mencionados ha deparado análisis interesantes en las principales escuelas de negocios como ejemplo de abordaje de estrategias de mercadeo orientadas a "la base de la pirámide", es decir, los sectores con menos recursos (D’Andrea, Silva, \& Prado, 2008).

Por otro lado se aprecia una característica adicional en estos nuevos medios: además de informar y entretener se presentan como periódicos "de servicios". Como sostienen Armentia Vizuete y Caminos Marcet (2003), este tipo de publicaciones configuran un nuevo estilo influenciado por el norteamericano USA Today (lanzado en 1982 y de exponencial crecimiento en los últimos cinco años) en el que se persiguen nuevos planteamientos informativos a partir de lo que consideran las nuevas necesidades del lector y se organizan a través de un formato de lectura rápida. En esta estructura renovada comienzan a ocupar un lugar privilegiado aspectos que hasta no hace mucho no tenían más que un espacio marginal en la prensa, como las notas y consejos sobre calidad de vida, viajes, salud, alimentación, así como cuestiones relacionadas con la familia, la estética y otras instancias orientadas al consumo. Estos aspectos conforman una sinergia inmejorable con otras estrategias de marketing como los programas de fidelización y promociones especiales, al igual que los obsequios extraperiodísticos.

\section{A modo de cierre}

La propia dinámica del mercado periodístico parece haber quebrado la dicotomía entre el periodismo 'serio' y 'sensacionalista' o 'popular' para organizar una eficiente segmentación de públicos y objetivos de ventas. A partir de precisiones relacionadas con las competencias de los diversos sectores ( $\mathrm{y}$, fundamentalmente de la complejización del análisis de sus capacidades económicas), los departamentos de marketing lograron que convivan en armonía enfoques del periodismo que anteriormente se definían como antagónicos. El análisis del caso argentino, que permite tender lazos con otros países de la región, parece mostrar que más que una colonización de las estéticas irreverentes, se reordenó el mapa cultural en sus diversos estratos. Simultáneamente se pone en cuestión la noción de legitimidad cultural que primó durante la Modernidad, y la manera en la que en la actualidad el capital y el Estado piensan el espacio social y la cultura.

Bastante alejados del dramatismo y la emotividad que los caracterizó en sus orígenes, se observa una tendencia a apostar a la depuración de ciertos elementos ligados a la violencia y lo truculento. Paralelamente se reconocen ciertas características positivas de la prensa popular (la incorporación de temáticas y problemas ligados a los sectores populares, la incorporación de lectores a través de estrategias específicas de captación de públicos, etc.) en medios "serios" que parecen, a su vez, haber incorporado lógicas y prácticas que años anteriores denostaban. Puede observarse un sutil proceso de nivelación: una tendencia a la homogenización estilística que deja de lado 
las formas más "extremas" por fuera del mercado o para productos marginales. Un claro ejemplo, es lo que ocurre con las publicaciones de casos policiales que apelan a lo truculento, que ya no tienen referentes en el área. Estas temáticas, que han sido incorporadas en lugares centrales por parte de la prensa seria a partir de la lógica de la "inseguridad", han modificando notablemente el enfoque (Kessler, 2009).

Los nuevos diarios populares se autodefinieron como consecuencia del ocaso de la prensa popular tradicional y propusieron una fuerte reconversión: una prensa cuyo modelo es definitivamente el entretenimiento y que propone que la construcción ciudadana se da por las pequeñas historias, la prestación de servicios y una estética que tiene como centro de referencia a la televisión y, en menor medida, a las nuevas tecnologías. Es explícita la referencia a cierto proceso de modernización que incluyó una reducción de sus elementos más cuestionables, como las portadas truculentas. Sin embargo, eso no convirtió a los medios en difusores más democráticos ni se establecieron lugares comunes para la participación de los sectores populares.

La versión "populista" (incluso en las formas previas, que se observaron a principios de siglo) tuvo un fuerte envión democratizador que otorgó visibilidad a lo subalterno, y durante buena parte del siglo xx se pudo ampliar esa visibilidad acotada representando a sujetos, espacios y problemas que no formaban parte del espacio público mediatizado.

Lo que ese envión no pudo prever es que podía convertirse en conservadora, como se observó en el proceso de plebeyización de los años 90: un nuevo reordenamiento de la base y la superestructura social que produjo nuevas apropiaciones de ese exceso subalterno, en tanto había perdido su carácter contestatario. En el caso de la prensa, específicamente, el sensacionalismo como expresión de la experiencia vívida del mundo popular pierde significación y puede ser extendida a otros medios en su versión securitaria y estigmatizadora.

La contracara liberal de ese periodismo, que en otro momento se enfrentó a ese desvío amarillista, no hizo más que reconstruir la violencia simbólica mediante la imposición de un arbitrario cultural que es requerido pero a la vez imposible de cumplir, como describió Bauman (1997). Este periodismo, no pudo ver que era parte del problema y no de la solución, por tal motivo abandonó la esfera pública para recluirse fuera de los medios masivos o segmentando estos, reafirmando nuevas arbitrariedades culturales de distinción. De alguna manera, se negoció ese estigma de degradación y decadencia del periodismo y se convirtió en negocio.

Los estudios sobre cultura popular (y en general, los estudios sobre comunicación y cultura) tienen como desafío repensar el rol de lo subalterno: su construcción, su representación y su crítica. Como indicaba hace treinta años Stuart Hall (1984), estos estudios siguen permitiendo dar cuenta de las oscilaciones de las producciones culturales en relación con las demás dinámicas sociales, al mismo tiempo que permiten construir sociedades que sean finalmente mejores para vivir.

\section{Agradecimiento}

Agradezco especialmente a las/os revisoras/es anónimos, cuyos aportes han brindado más solidez a una versión preliminar del presente trabajo. 


\section{Referencias}

1. Adamovsky, E. (2012). Historia de las clases populares en la Argentina: desde 1880 hasta 2003. Buenos Aires: Editorial Sudamericana.

2. Alabarces, P., \& Silba, M. (2014). «Las manos de todos los negros, arriba»: Género, etnia y clase en la cumbia argentina. Cultura y Representaciones Sociales, 8(16), 52-74. Recuperado de http://www.journals. unam.mx/index.php/crs/article/view/44846

3. Amaral, M. F. (2006). Jornalismo Popular. São Paulo: Editora Contexto.

4. Armentia Vizuete, J. I., \& Caminos Marcet, J. M. (2003). Los formatos de lectura rápida como seña de identidad visual del diario de servicios. Doxa Comunicación: revista interdisciplinar de estudios de comunicación y ciencias sociales, (1), 11-34. Recuperado de http://recyt.fecyt.es/index.php/doxacom/article/view/35789

5. Arribá, S. (2009). El Peronismo y la Política de Radiodifusión 1946 - 1955. En G. Mastrini (Ed.), Mucho ruido, pocas leyes: economía y políticas de comunicación en la Argentina, 1920-2007 (2. ed. ampliada). (71-100) Buenos Aires, Argentina: La Crujía Ediciones.

6. Arsenault, A., \& Castells, M. (2008). Switching power: Rupert Murdoch and the global business of media politics. A sociological analysis. International Sociology, 23(4), 488-513. Doi: http://doi.org/10.1177/ 0268580908090725

7. Awad, I., \& Soto, G. (2001). Popularidad de «La Cuarta»: La clave está en el lenguaje. Cuadernos de Información, 14, 48-62. Recuperdo de http://cuadernos.info/index.php/CDI/article/view/181

8. Bauman, Z. (1997). Legisladores e intérpretes: sobre la modernidad, la posmodernidad y los intelectuales. Buenos Aires: Universidad Nacional de Quilmes.

9. Becerra, M. (2010). Las noticias van al mercado: etapas de intermediación de lo público en la historia de los medios de la Argentina. En G. E. Lugones \& J. Flores (Eds.), Intérpretes e interpretaciones de la Argentina en el bicentenario. (139-165). Bernal: Universidad Nacional de Quilmes Editorial.

10. Becerra, M. (2015). Transgresión, propaganda, convergencia y concentración. El sistema de medios en el kirchnerismo. En C. Gervasoni \& E. Peruzzotti (Eds.), ¿Década ganada?: evaluando el legado del kirchnerismo. (89-111). Buenos Aires: Debate.

11. Campbell, W. J. (2001). Yellow journalism: puncturing the myths, defining the legacies. Westport, Conn.: Praeger.

12. Cappellini, M. (2004). La prensa chicha en Perú. Chasqui - Revista Latinoamericana de comunicación, 88, pp. 32-37.

13. Carlson, M., \& Berkowitz, D. (2014). 'The emperor lost his clothes': Rupert Murdoch, news of the world and journalistic boundary work in the UK and USA. Journalism, 15(4), 389-406. Doi: http://doi.org/10.1177/ 1464884913477280

14. Checa Montúfar, F. (2003). El «Extra»: las marcas de la infamia : aproximaciones a la prensa sensacionalista. Quito: Universidad Andina Simón Bolívar.

15. D’Andrea, G., Silva, J., \& Prado, M. (2008, julio 15). Trome: News for the Base of the Pyramid. Harvard Business Review. 
16. Díaz Nosty, B. (2007). Medios de comunicación : tendencias'07 : el escenario iberoamericano. Barcelona; Madrid: Editorial Ariel; Fundación Telefónica.

17. Fontcuberta, M. (2006). El periódico en una sociedad compleja. En M. Fontcuberta \& H. Borrat, Periódicos : sistemas complejos, narradores en interacción. (15-155). Buenos Aires: La Crujía.

18. García, H. R. (1993). Cien veces me quisieron matar. Buenos Aires: Planeta.

19. Gargurevich Regal, J. (2000). La prensa sensacionalista en el Perú. Lima: pucp Fondo Editorial.

20. Gargurevich Regal, J. (2002). La"chicha", cultura urbana que resiste. Comunicación. EAP Universidad Nacional Mayor de San Marcos, 2(3), (23-30).

21. Gualda, D. (2011, abril 17). Entrevista por Redacción Noticias Urbanas [Transcripción]. Recuperado de http://www.noticiasurbanas.com.ar/noticias/79f7aad28130f09e1c0b1e8143f6749c/

22. Habermas, J. (2004). Historia y crítica de la opinión pública: la transformación estructural de la vida pública. Barcelona: Gustavo Gili.

23. Hall, S. (1984). Notas sobre la desconstrucción de «lo popular». En R. Samuel (Ed.), Historia popular y teoría socialista. (93-110). Barcelona: Editorial Crítica.

24. Karush, M. (2013). Cultura de clase. Radio y cine en la creación de una Argentina dividida (1930-1946). Buenos Aires: Ariel.

25. Keightley, E., \& Punathambekar, A. (2012). Tabloid journalism: the News of the World scandal and beyond. Media, Culture \& Society, 34(5), 623-624. Recuperado de http://doi.org/10.1177/0163443712442705

26. Kessler, G. (2009). El sentimiento de inseguridad: sociología del temor al delito. Buenos Aires: Siglo Veintiuno Editores.

27. Lanza, C. (Ed.). (2010). La chica mala del periodismo. Crónica ROJA en Bolivia. La Paz: Friedrich Ebert Stiftung - Centro de Competencia en Comunicación para América Latina.

28. Lobato, M. Z. (2009). La prensa obrera: Buenos Aires y Montevideo, 1890-1958. Buenos Aires: Edhasa.

29. Macassi Lavander, S. (2001). Prensa amarilla y cultura política en el proceso electoral. Lima: Asociación de Comunicadores Sociales Calandria.

30. Martín-Barbero, J. (agosto de 1983). Memoria Narrativa e industria cultural. Comunicación y Cultura, 10, pp. 59-73.

31. Martín-Barbero, J. (2010). De los medios a las mediaciones. Comunicación, cultura y hegemonía. Barcelona: Anthropos.

32. Mastrini, G., \& Becerra, M. (Eds.). (2006). Periodistas y magnates: estructura y concentración de las industrias culturales en América Latina. Buenos Aires: Instituto Prensa y Sociedad: Prometeo Libros.

33. McCombs, M. (2006). Estableciendo la agenda: el impacto de los medios en la opinión pública y en el conocimiento. Barcelona: Paidós.

34. McGuigan, J. (2000). El populismo cultural revisitado. Guaraguao, 4(10), 30-53. Recuperado de http:// www.jstor.org/stable/25596146

35. Pauner Chulvi, C. (2013). Privacidad y periodismo : el escándalo Murdoch sobre escuchas telefónicas en News of the World. Revista de Derecho Político, 1(88). Doi: http://doi.org/10.5944/rdp.88.2013.12787 
36. Piva, A. (2013). ¿Cuánto hay de nuevo y cuánto de populismo en el neopopulismo?: Kirchnerismo y peronismo en la Argentina post 2001. Trabajo y sociedad, (21), 135-157. Recuperado de http://www.scielo.org. ar/scielo.php?script=sci_arttext\&pid=S1514-68712013000200011\&lng=es\&nrm=iso\&tlng=es

37. Rincón, O. (2006). Narrativas mediáticas, o, cómo se cuenta la sociedad del entretenimiento. Barcelona: Gedisa.

38. Ross, E. A. (2001). La supresión de las noticias importantes. Reis, (94), 191-202. Doi: http://doi.org/10.2307/ 40184318

39. Saítta, S. (1998). Regueros de Tinta: El Diario «Crítica» en la Década de 1920. Editorial Sudamericana.

40. Schudson, M. (1981). Discovering The News: A Social History Of American Newspapers. The Perseus Books Group.

41. Steimberg, O. (1987). Prensa amarilla/Prensa blanca: nota sobre una conocida y no definida oposición de géneros. En J. B. Rivera \& E. Romano (Eds.), Claves del periodismo argentino actual. (149-159). Buenos Aires: Ediciones Tarso.

42. Steimberg, O. (2000). Naturaleza y cultura en el ocaso (triunfal) del periodismo amarillo. Recuperado de http://www.redalyc.org/resumen.oa?id=93500512

43. Sunkel, G. (1985). Razón y pasión en la prensa popular: un estudio sobre cultura popular, cultura de masas y cultura política. ILET - Instituto Latinoamericano de Estudios Transnacionales.

44. Sunkel, G. (2002). La prensa sensacionalista y los sectores populares. Bogotá: Grupo Editorial Norma.

45. Svampa, M. (2005). La sociedad excluyente: la Argentina bajo el signo del neoliberalismo (1. ed). Buenos Aires: Taurus.

46. Svampa, M. (2011). Argentina, una década después. Del «que se vayan todos» a la exacerbación de lo nacional-popular. Nueva sociedad, (235), 17-34.

47. Torrico, E. (1999). El negocio sensacionalista en Bolivia. Una lógica empresarial que se impone. Punto Cero, (5), pp. 76-84. 